\title{
COOPERAÇÃO INTERNACIONAL E OS RECURSOS HÍDRICOS TRANSFRONTEIRIÇOS: SOBERANIA E INSTITUIÇÕES INTERNACIONAIS
}

\author{
Fernanda Mello Sant'Anna*
}

\section{RESUMO:}

Este artigo analisa como diversos autores dentro das teorias de relações internacionais e da geografia política interpretam a cooperação internacional, em especial, no caso dos recursos hídricos. Este mosaico de teorias permite uma compreensão mais abrangente de como ocorre a cooperação internacional para a gestão dos recursos hídricos transfronteiriços. Para entender o funcionamento da cooperação internacional é necessário também analisar o Estado e sua relação com o território e a soberania estatal, pois os Estados, ao firmarem compromissos, se preocupam em garantir a sua soberania. Finalmente, é analisada a criação de instituições internacionais para a gestão compartilhada dos recursos hídricos transfronteiriços.

\section{PALAVRAS-CHAVE:}

Cooperação internacional, recursos, hídricos, transfronteiriço.

\section{ABSTRACT}

This article analyses how authors inside international relations theory and political geography interpret international cooperation, especially in the case of water resources. This mosaic of theories provides a wider comprehension of international cooperation in the transboundary water resources management. To understand how international cooperation woks is necessary to analyse the State and its relation to the territory and state sovereignty, therefore the State always consider its sovereignty when signing agreements. Finally, it is analysed the creation of international institutions to the transboundary water resources joint management.

\section{KEYWORDS:}

Cooperation international, resources, water, transboundary.

\section{Introdução}

Este artigo tem como objetivo analisar como diversos autores dentro das teorias de relações internacionais e da geografia política interpretam a cooperação internacional, em especial, no caso dos recursos hídricos. Este mosaico de teorias permite uma compreensão mais abrangente de como ocorre a cooperação internacional para a gestão dos recursos hídricos transfronteiriços. Portanto, trata-se de uma revisão da literatura sobre o tema, que se mostra oportuna dada a premência em resolver emergentes conflitos por uso de águas transfronteiriças.

Para entender o funcionamento da cooperação internacional é necessário também analisar o Estado e sua relação com o território e a soberania estatal, pois os Estados, ao firmarem compromissos, se preocupam em garantir a sua soberania. Finalmente, é analisada a criação de instituições internacionais para a gestão compartilhada dos recursos hídricos 
transfronteiriços. Para tal, está dividido em quatro partes: meio ambiente, território e soberania, mostra como a questão ambiental está ligada ao território; cooperação internacional, que analisa diferentes visões sobre o tema; soberania estatal, que avalia a dificuldade dos Estados exercerem sua soberania junto a temas ambientais e, por fim, instituições e a gestão dos recursos hídricos transfronteiriços, que discute os limites que elas enfrentam na resolução de conflitos ambientais.

\section{Meio ambiente e território}

Cooperação internacional resulta de processos sociais e políticos que pode abarcar tanto países quanto instituições internacionais. Quando se trata de recursos hídricos transfronteiriços, torna-se um relevante instrumento para a gestão compartilhada, o que colabora para a diminuição de conflitos políticos. Este artigo, por meio de contribuições das teorias das relações internacionais e da geografia política analisa a cooperação internacional, em especial, em torno dos recursos hídricos transfronteiriços.

Nas análises sobre as questões ambientais muitas vezes se esquece de mencionar a dimensão territorial. No período atual, são os Estados que exercem o domínio político sobre uma determinada porção do espaço, o território. O Estado pode ser definido como "aquela comunidade humana que, dentro de determinado território - este, o 'território', faz parte da qualidade característica -, reclama para si (com êxito) o monopólio da coação física legítima" (WEBER, 1999, p. 525). Na geografia política encontra-se também a seguinte definição de Estado: "quando uma população instalada num território exerce a própria soberania" (MUIR apud RAFFESTIN, 1993, p. 22).

O território é entendido como "uma área de exercício de um poder estatal" (MORAES, 2006, p. 11). Ainda segundo MORAES (2005), o território é o âmbito espacial onde se exerce o poder:

o poder é passível de ser apreendido enquanto ação e o âmbito espacial de sua realização circunscreve o território, o qual se apresenta assim como área de prática de um poder. Nessa concepção, o território é, antes de tudo, um espaço de dominação, o âmbito espacial de um domínio político (mesmo que circunstancial e momentâneo) (MORAES, 2005, p. 117).

RAFFESTIN (1993) diferencia espaço de território. Para ele, o espaço existe anteriormente ao território, pois é a partir da apropriação de um espaço que a sociedade produz o seu território. Desta forma, a sociedade não pode escapar da dimensão territorial, pois ao se constituir ela conforma seu espaço (HAESBAERT e PORTO-GONÇALVES, 2006). Para Ratzel o território é universal no sentido de que os seres humanos sempre se apropriam do espaço:

que o território seja necessário à existência do Estado é coisa óbvia. Exatamente porque não é possível conceber um Estado sem território e sem fronteiras é que vem se desenvolvendo rapidamente a geografia política; e embora mesmo a ciência política tenha frequentemente ignorado as relações de espaço e a posição geográfica, uma teoria de Estado que fizesse abstração do território não poderia jamais, contudo, ter qualquer fundamento seguro. [...] É fácil convencer-se de que do mesmo modo como não se pode considerar mesmo o Estado mais simples sem o seu território, assim também a sociedade mais simples só pode ser concebida junto com o território que lhe pertence (RATZEL apud MORAES, 1990, p. 73).

A organização do espaço geográfico em Estados não é um produto "natural", os Estados se formaram ao longo de um processo histórico na Europa, com a centralização do poder dos reis.

Este modelo de Estado foi levado para outras partes do mundo, que o construíram a partir de outros contextos sociais, históricos, políticos e econômicos. Isto resultou em diferentes tipos de Estado. No início do século $X X$, o mundo passa a ser uma contiguidade ininterrupta de Estados, onde é praticamente impossível ignorar a existência e as ações dos demais:

los grandes Estados del mundo se tocan, ya directamente, ya sirviendo de intermediarios 
los pequeños Estados organizados como ellos; las formas de las sociedades políticas complejas se han extendido o están en camino de extenderse a toda la parte habitable de la tierra. No se registra transformación tan profunda ni tan rica en consecuencias, en la historia del globo, como este advenimiento de la contigüidad sin interrupción de los Estados. [...] Hoy día ningún gran Estado puede ignorar la existencia y la acción de otro gran Estado, por lejos que estén uno de otro (VALLAUX, 1914, p. 309-310).

Para COSTA (1992) a condição de moderno do Estado resolve a questão de sua origem histórica, porém, não se pode falar de um caráter geral para todos os Estados, pois cada Estado surgiu em um contexto histórico, geográfico e socioeconômico próprio, o que implica diferenças entre eles. O Estado-nação, por exemplo, é uma forma muito específica de Estado que é encontrado em apenas algumas partes do mundo. De acordo com SÁNCHEZ (1992), a ideia de nação vem da vinculação social que se cria dentro de um mesmo território, conformando uma cultura comum, independentemente da origem racial (biológica) ou étnica das pessoas da comunidade. Quando essa consciência sociocultural que é a nação coincide com o domínio do território em que vivem trata-se de um Estadonação. No entanto, existem Estados que abarcam várias nações em seu interior e também existem nações divididas em vários territórios. Este mesmo autor adverte que as ideias de nação e de nacionalidade foram formuladas a partir de uma concepção eurocêntrica da história e da geografia política (SÁNCHEZ, 1992).

De acordo com MORAES (2005) é intrinsecamente territorial a universalização da forma estatal de dominação social, já que muitos são os exemplos de construção de Estados territoriais que precederam a nação. A construção da nação é, muitas vezes, um projeto estatal posterior à criação do Estado, e em alguns casos o Estado é criado sem qualquer legitimidade interna (MORAES, 2005). Os Estados periféricos (muitos dos quais já foram colônias ou estiveram sob domínio imperialista) não são em geral nacionais, mas são "ao mesmo tempo soberanos e dependentes, injustos e efetivos; e, conjuntamente com a prática da consolidação de seu poder e da dominação interna, são agentes fundamentais na internacionalização do uso de seus recursos e territórios" (MORAES, 2005, p. 117).

No caso do Brasil a formação do Estado moderno foi muito diferente do que na Europa, em primeiro lugar porque o Brasil foi uma colônia até o século XIX. De acordo com MORAES (2006), a dimensão espacial é uma questão central para os países que foram colonizados, isto se deve ao fato de que a própria colonização é o resultado de uma conquista territorial. Nesse sentido, o Estado que se forma no Brasil partiu de um território colonial, herdando algumas de suas características:

[...] a formação do Estado no Brasil vai estar continuamente marcada por uma forte orientação de cunho geopolítico: garantir a soberania e a integridade dos fundos territoriais será sempre sua missão básica. Daí um aparelho de Estado construído tendo por referência o domínio do território e não o bemestar do povo (MORAES, 1994, p.15).

O território colonial é formado também por áreas onde não existe ainda uma ocupação, ou melhor, que ainda não foram incorporadas aos fluxos colonizadores, e desta foram, são denominados de fundos territoriais. Com a independência das colônias esses fundos territoriais são incorporados ao território nacional (MORAES, 2006). No Brasil, as ideias de conquista do território e construção do país são vistas como heranças do período colonial, que tem como objetivo ocupar os fundos territoriais. Esta ideia de conquista é evidente no caso da Amazônia brasileira.

A Amazônia é incorporada ao território colonial através do Tratado de Madrid de 1750, pelo qual boa parte do território amazônico que pertencia à Espanha passa a ser de Portugal. No entanto, sua ocupação atendeu a diversos interesses. Após a independência e durante o império brasileiro 
a importância dada à região amazônica foi devido à necessidade de consolidação das fronteiras (ANTIQUERA, 2006).

Os Estados, portanto, foram criados em contextos diferentes, mas compartilhando alguns pressupostos como o de território e o de soberania. Outra característica fundamental do Estado é o seu papel de administrador, isto é, a constituição de sua burocracia estatal. Esta burocracia também tem um papel importante nas relações entre os Estados, pois pode interferir na formulação da política externa.

O Estado não age como um ator unitário no sistema internacional, ele é centro de conflitos e oposições entre diferentes grupos da sociedade que disputam o poder para imporem os seus interesses através do aparato do Estado (HALLIDAY, 2007; SÁNCHEZ, 1992). Novas teorias da ciência política e da sociologia vêem o Estado como "um conjunto de organizações administrativas, políticas e militares encabeçadas e mais ou menos bem coordenadas por uma autoridade executiva" (HALLIDAY, 2007, p. 92). Entre estas teorias destaca-se a da análise decisória, que surgiu contra a visão do Estado homogêneo, único e abstrato, com uma divisão de tarefa perfeita, e sempre racional. Pelo contrário, ela percebe uma dinâmica interna no Estado, que pressupõe uma relação entre os diversos interesses dos atores envolvidos nas estruturas administrativas e no poder político (Executivo) do Estado.

Foi Graham Allison quem desenvolveu um modelo teórico do processo decisório, e seus estudos foram complementados pelos de Morton Halpering. No modelo político burocrático a decisão governamental é na verdade o resultado de um jogo político de negociações e barganha. Este modelo explica os desvios da racionalidade ideal que aparecem no momento da decisão política, demonstrando como as rotinas das organizações (burocracias estatais) constrangem as formações de opções, além de explicar os desvios no momento da instrumentalização das decisões, revelando como as rotinas afetam a sua implementação.
HALLIDAY (2007) aponta que a distinção entre Estado e governo também é necessária para explicar, por exemplo, quando certas burocracias dentro de um Estado se opõem a certas políticas do governo (Executivo). Neste caso, e Estado pode ser identificado com o aparato administrativo, enquanto governo é o pessoal executivo. A administração do Estado abarca a gestão do seu interior e as relações com o exterior. A gestão interior, de acordo com SÁNCHEZ (1992, p. 110):

abarca todos los ámbitos culturales, económicos, educativos, sanitarios y un largo etcétera. Es decir, todos aquellos ámbitos relacionados con la satisfacción de las necesidades básicas y de las necesidades sociales. Para ello debe gestionar la actuación de las instituciones sociales, así como gestionar el territorio, para lo cual se servirá de políticas específicas encaminadas a alcanzar cada objetivo particular.

Outra questão importante ao se analisar o Estado, e em particular as relações entre os Estados, são as fronteiras políticas. Os recursos hídricos transfronteiriços são aqueles rios e lagos que atravessam a fronteira entre dois ou mais Estados, e aqueles rios e lagos que coincidem com os limites da fronteira entre dois ou mais países.

O mundo tornou-se dividido politicamente em Estados separados pelas fronteiras políticas. As fronteiras são limites móveis, que podem ser mudados ao longo da História. Neste sentido, a fronteira apenas mostra os limites em um momento dado, mas ela pode ter sido diferente no passado, e pode mudar no futuro: "la frontera política representa un límite coyuntural histórico, o lo que es lo mismo, un momento del equilibrio dinámico del proceso histórico" (SÁNCHEZ, 1992, p. 174).

PRESCOTT (1965) concorda com FAWCET (apud PRESCOTT, 1965), ao fazer distinção entre fronteira (zona) e fronteira (limite). Para Machado (2002) a origem da palavra fronteira demonstra que ela não estava associada a nenhum conceito jurídico e remetia não ao fim da unidade política e sim, onde ela poderia se expandir. Já a palavra 
limite é usada para "designar o fim daquilo que mantém coesa uma unidade político-territorial" (MACHADO, 2002). Portanto, a noção de fronteira como limite político-jurídico separando os territórios estatais surge com o Estado moderno, juntamente com o princípio da soberania.

As fronteiras políticas são o "elemento definidor de los límites territoriales de los estados, como barreras políticas territoriales a escala internacional" (SÁNCHEZ, 1992, p. 174). Michel FOUCHER (apud COSTA, 1992) aponta que cada fronteira é uma singularidade, pois apresenta contextos diversos e, desta forma, não é possível aplicar as clássicas definições de fronteira para todas as situações do mundo.

COELHO (1992) aponta que nas últimas décadas "tem se verificado uma evolução muito intensa do conceito de fronteira, não só em sentido estrito, mas em função de sua aplicação a fenômenos tipicamente contemporâneos" (COELHO, 1992, p. 20). O caso da União Europeia é um exemplo que se destaca, e que foi analisado por RAFFESTIN e GUICHONNET (apud COSTA, 1992). Estes autores definem as fronteiras entre os países europeus membros da Comunidade Europeia como uma zona fronteiriça de integração. As fronteiras internacionais passam a significar não apenas um limite divisório, estratégico que acarreta preocupações em relação à defesa e segurança, e sim uma área propícia à cooperação.

A geógrafa Lia Osório MACHADO (2002) analisa as áreas situadas na zona (ou faixa) de fronteira que são chamadas de regiões transfronteiriças. Para MACHADO e STEIMAN (2002) "a zona de fronteira seria composta pelas faixas de cada lado do limite internacional, caracterizando-se por interações que, embora internacionais, criam um millieu próprio de fronteira, só perceptível na escala local/regional" (p. 11-12). No Brasil a faixa de fronteira estendese $150 \mathrm{~km}$ ao longo de toda a fronteira brasileira onde estão previstos comportamentos diferenciados ligados à segurança nacional. No Peru e na Bolívia a faixa de fronteira tem $50 \mathrm{~km} \mathrm{e}$ também está previsto em suas constituições comportamentos especiais nestas áreas (STEIMAN, 2002).
As regiões fronteiriças (ou transfronteiriças), em sua maioria, estão isoladas dos centros nacionais de seus respectivos Estados e, também, das comunidades do Estado vizinho. Em geral, apresentam ausência (ou precariedade) de redes de transporte e de comunicação, pois possuem um peso político e econômico menor em relação aos centros nacionais:

por outro lado, as regiões de fronteira estão também formalmente isoladas dos Estados vizinhos pelo papel disjuntor dos limites políticos. Sem instituições para instrumentála, a cooperação entre países vizinhos em regiões de fronteira tem sido feita informalmente, e através de acordos tácitos entre as autoridades locais dos países fronteiriços (MACHADO e STEIMAN, p.7-8).

Para a geógrafa Lia MACHADO (1998) o processo atual, que vem ocorrendo ao longo das fronteiras voltado para a cooperação ou integração, indica, mais do que uma perda da função dos limites e fronteiras internacionais, uma mudança da perspectiva do Estado em relação ao próprio papel da fronteira. A fronteira, anteriormente, era concebida a partir das estratégias e interesses do Estado central, porém, nas últimas décadas, passa a ser idealizada e transformada, também, pelas comunidades de fronteira, e pelos governos subnacionais. Trata-se da "possibilidade real de comunidades locais estenderem sua influência e reforçarem sua centralidade além dos limites internacionais e sobre a faixa de fronteira" (MACHADO e STEIMAN, 2002, p. 8).

Existem iniciativas locais nas regiões de fronteira no mundo e, em especial na América do Sul, que buscam intensificar as relações das comunidades fronteiriças. Em geral, essas regiões fronteiriças ou transfronteiriças, não contam na prática com uma legislação específica nem com projetos governamentais dedicados a seu desenvolvimento e cooperação. Quando existem ações neste sentido estas são iniciativas dos governos nacionais que atuam sobre suas respectivas regiões fronteiriças (MACHADO e STEIMAN, 2002). 
Para MACHADO e STEIMAN (2002) existe um potencial nas regiões fronteiriças para deslanchar a cooperação internacional entre os países fronteiriços, porém também existe uma influência sobre elas do contexto internacional. Coexistem, portanto, nestas regiões elementos de integração e de desintegração. As iniciativas de integração são, em muitas regiões, fruto do interesse de suas próprias elites e governos. Estas autoras afirmam ainda que uma questão fundamental para as cidades e regiões fronteiriças "é, portanto, a de como se inserir nas diversas redes transnacionais que as atravessam, sem desempenharem fatalmente o papel de mero ponto de passagem" (MACHADO e STEIMAN, 2002, p. 10).

As fronteiras políticas separam os Estados, mas não separam muitos de seus recursos naturais, entre eles a água contida em bacias hidrográficas transfronteiriças. Atualmente, em algumas partes do mundo, as fronteiras políticas que apenas separavam os territórios dos Estados são agora zonas fronteiriças de integração e articulação devido, em grande parte, à interdependência entre os Estados, ocasionada, por exemplo, pelos recursos hídricos transfronteiriços. Desta forma, percebe-se que a questão da fronteira está diretamente ligada à questão da interdependência e da cooperação internacional. Como afirmam STEIMAN e MACHADO (2002), no caso das fronteiras entre México e Estados Unidos e entre o Brasil e os países do Cone Sul os recursos hídricos transfronteiriços atuaram como incentivador da cooperação:

o caso da fronteira do México e os Estados Unidos é paradigmático. Apesar do problema imigratório ser muito antigo e fonte de antagonismo de parte a parte, os primeiros protocolos de cooperação entre os dois países surgiram em função da questão hídrica. Essa tendência de criar comissões/empresas de gestão de recursos hídricos em zonas de fronteiras internacionais e administrá-los de forma compartilhada se confirma, aliás, em outras partes do mundo, inclusive no Brasil (caso da Hidrelétrica de Itaipu no início da década de 1970) (MACHADO e STEIMAN, 2002, p. 7).
Os recursos naturais presentes no território de um Estado está sob o poder político deste. Para RAFFESTIN (1993), os recursos são fruto de uma relação, que é também política, pois foram apropriados pelos seres humanos e são, portanto, frutos de "uma concepção histórica da relação com a matéria, que cria a natureza sóciopolítica e sócio-econômica dos recursos" (RAFFESTIN, 1993, p. 225).

A produção dos recursos naturais envolve o uso da técnica dentro de um dado período histórico e em uma porção do território, que se traduz no problema do acesso, pois os recursos estão distribuídos de modo desigual no planeta:

a produção dos recursos supõe, pois, uma dominação mínima de uma porção do quadro espaço-temporal dentro do qual, e para o qual, a tecnicidade interage com a territorialidade. A relação com a matéria é, portanto, ipso facto, uma relação com o espaço e com o tempo. É todo o problema do acesso que assim se coloca: acesso no espaço e/ou acesso na duração. Durante decênios, as potências industriais tiveram acesso espacial e temporal ao petróleo; depois, as coisas mudaram (RAFFESTIN, 1993, p. 228).

\section{Entretanto,}

a busca e acesso a recursos naturais pelo planeta gerou muitos embates no passado. Também é verdade que estimulou o comércio entre países. Porém, a manter-se o modo de acumulação capitalista, cujas temporalidades desconsideram a capacidade natural de reposição de recursos naturais, quando são renováveis, ou mesmo a degradação ambiental que geram, as dificuldades em obter recursos serão ampliadas, despertando muito inquietação (RIBEIRO, 2004a, p. 75).

Os Estados precisam ter acesso a um recurso natural para usufruírem dele. A água é um recurso renovável e finito que está distribuído de maneira desigual, isto é, "sua distribuição natural não corresponde à sua distribuição política" (RIBEIRO, 2008, p. 17). Portanto, a água, como qualquer outro recurso, pode ser motivo 
de poder e conflitos entre os Estados e entre outros atores sociais, pois o "controle e/ou a posse da água são, sobretudo, de natureza política, pois interessam ao conjunto de uma coletividade" (RAFFESTIN, 1993, p. 231). A água é um dos recursos mais indispensáveis à vida. O uso inadequado resulta em sua degradação, o que exige sua gestão e controle.

As relações políticas em torno da água precisam ser compreendidas dentro da questão do território e da soberania, conforme afirma o geógrafo Wagner RIBEIRO (2008). Quando as relações entre os Estados envolvem os recursos hídricos transfronteiriços, as ações de um Estado podem ter impacto em outro, o que revela uma situação de interdependência. No caso de rios transnacionais isto é bem evidente, pois a poluição gerada no Estado à montante causará impactos no Estado à jusante. Esta situação pode levar ao conflito entre os Estados envolvidos. Porém, estes Estados podem optar por cooperar para buscarem soluções conjuntas para os problemas em torno dos recursos hídricos. Além do que, a atual crise da água, resultado de um consumismo crescente, em conjunto com sua distribuição desigual no mundo, faz com que os países que detêm grande estoque hídrico possam "vir a ser alvo de cobiça internacional e precisam prepararse para enfrentar novos desafios" (RIBEIRO, 2008, p. 76).

Os Estados sendo soberanos decidem de que forma podem resolver os problemas envolvendo os recursos hídricos transfronteiriços, através da cooperação ou do conflito. A cooperação exige a criação de normas, instituições e padrões de comportamento para que seja efetiva. O conflito armado por recursos hídricos não é um fato novo. No caso de bacias internacionais, é emblemático o conflito envolvendo Israel e Jordânia referente à bacia do rio Jordão.

De acordo com ROBBINS (2003), os recursos hídricos são um excelente tema de estudo para a geografia política. No caso dos rios transfronteiriços, estes desafiam as fronteiras políticas, podendo resultar em coalizões entre
Estados ribeirinhos e criar incentivos tanto para o conflito internacional quanto para a negociação (ROBBINS, 2003, p. 642).

\section{Cooperação internacional}

Ao analisar as relações internacionais nos últimos anos, nota-se o aumento da cooperação entre os países, com a assinatura de tratados internacionais, a criação de blocos econômicos, áreas de livre comércio e organizações internacionais. Para compreender este cenário atual é preciso rever a noção de cooperação internacional, quem são os atores envolvidos, seus meios e seus objetivos. Os países, sendo os principais atores das relações internacionais, têm diferentes definições e percepções dos problemas mundiais, permanecendo em aberto a questão de como fazer com que os diferentes atores busquem soluções compartilhadas.

A cooperação é entendida como oposta ao conflito e à competição. No entanto, a maioria dos autores discorda em relação ao que causa a cooperação. Para Keohane, um número considerável de pesquisadores define cooperação como "when actors adjust their behavior to the actual or anticipated preferences of others, through a process of policy coordination" (KEOHANE, 1984, p. 51). Desta forma, a cooperação internacional é um processo de coordenação política entre os atores, que ajustam os seus comportamentos de acordo com as preferências estabelecidas em conjunto para atingirem expectativas comuns. Tal definição buscava responder por que os Estados cooperariam em um sistema anárquico, e pressupõe que o comportamento dos atores é direcionado por um objetivo, o que permite o ajustamento das políticas dos atores, e, sendo assim, os Estados ao cooperarem teriam melhores resultados do que o contrário.

A cooperação entre os Estados se tornou mais ampla e mais frequente nas relações internacionais das últimas décadas, quando surgiram novas teorias para explicá-las. Após a Primeira Guerra Mundial, a cooperação internacional emergiu, de acordo com SOARES 
(2003) "como uma condição necessária para que os Estados viessem a alcançar qualquer objetivo internacional, por mais corriqueiro que fosse" ( $p$. 603). A diplomacia multilateral ganha relevância após 1919, no entanto, somente no final da década de 1940 , se pode assistir realmente à introdução da cooperação internacional na agenda das relações exteriores dos Estados, contribuindo para tal a constituição do sistema das Nações Unidas (SOARES, 2003, p. 604).

Atualmente, as novas teorias da cooperação vêem esta como um processo aberto, descentralizado, não-linear e repetitivo, que pode ter um impacto de transformação nos atores e no funcionamento do sistema internacional (BALSIGER, 2004). Como processo não-linear significa dizer que ocorrem retrocessos e avanços, o que torna ainda mais complexo o seu entendimento.

A definição de cooperação ${ }^{1}$ utilizada neste trabalho é aquela que vai além da concepção tradicional de cooperação e a vê como um processo gradual não-linear e aberto que sofre influência de fatores domésticos e internacionais, e que pode causar transformações nos próprios atores e no sistema internacional.

Para SOARES (2003), no Direito Internacional, a cooperação internacional (lato sensu) é definida como:

\begin{abstract}
as ações conjuntas levadas a cabo entre todos os Estados ou por um certo número de Estados, com vistas a um determinado fim, seja aquelas concertadas em nível bilateral ou multilateral (dentro dos mecanismos existentes no interior das organizações ou entidades institucionalizadas ou em operações ad hoc), seja aquelas decorrentes de um dever instituído por uma norma não escrita (SOARES, 2003, p. 616).
\end{abstract}

A cooperação internacional pode produzir efeitos diversos nos Estados envolvidos, tais como: o alinhamento das respectivas políticas externas, com vistas a um fim pretendido, deveres previstos em normas de conduta precisa na esfera internacional, em particular, em tratados internacionais, e a internalização de normas internacionais nos ordenamentos jurídicos domésticos dos Estados (SOARES, 2003).

Para os autores da tradição do realismo político a cooperação é vista através do direito internacional, que busca assegurar a ordem do sistema de Estados, fundados sobre os princípios da soberania e da igualdade, já que a inexistência de uma autoridade acima dos Estados faz com que cada um seja responsável pela sua própria sobrevivência. Nesta visão, "os Estados emitiam, paulatinamente, as regras destinadas a assegurar sua auto-preservação na separação" (SMOUTS, 2004, p. 131). Entre os autores que compartilham esta visão estão MORGENTHAU (2004), ARON (2002) e CARR (2001).

Os neorrealistas, como WALTZ (1979), também partilham esta visão de que o Estado é o centro do sistema internacional e que este "resulta da interação de unidades semelhantes, os Estados, incitados pelas mesmas ambições e preenchendo as mesmas funções" (SMOUTS, 2004, p. 131). Os Estados são atores racionais que perseguem os seus próprios interesses. A cooperação serviria para manter a ordem internacional, em um sistema internacional anárquico e com suas unidades em competição. A anarquia do sistema internacional e a preocupação dos Estados com os ganhos relativos contribuem para que a cooperação não ocorra com frequência nas relações entre os Estados (DONELLY, 2005). A anarquia do sistema internacional é a grande responsável por esta situação, pois os Estados temem ser dominados ou enganados por outros Estados mais poderosos. A insegurança em relação às ações futuras dos outros Estados faz com que os Estados optem por não cooperar.

A principal contribuição desta teoria para a análise da cooperação internacional está na questão dos interesses dos Estados e também na busca destes em garantir a sua soberania. Para que a cooperação ocorra é necessário que existam objetivos comuns entre os Estados, porém, em determinados momentos outros interesses podem interferir no processo de cooperação. 
Uma visão contraposta a esta é a da teoria liberal, ou idealista, na qual a cooperação tem o papel de institucionalizar a vida internacional, com a criação de um direito internacional em prol das necessidades humanas. O idealismo foi a teoria que inspirou a criação da Liga das Nações e depois a Organização das Nações Unidas. A cooperação favoreceria a ação dos Estados em prol da realização de objetivos comuns (SMOUTS, 2004).

Já o neoliberalismo partilha de algumas suposições com os realistas, ambos vêem os Estados como atores racionais em um sistema anárquico, mas se diferenciam ao argumentar que a cooperação ocorre com mais frequência do que os realistas admitem, e que a paz é possível de ser alcançada (BURCHILL, 2005).

Dentro desta tradição liberal podemos diferenciar uma teoria mais idealista derivada da obra de Kant ( $A$ Paz Perpétua) e do pacifismo do século XIX, preocupada com a paz internacional, de uma teoria liberal mais voltada para a escolha racional (rational choice). A origem da teoria idealista remonta ao pacifismo europeu, que no século XIX se desligou do apelo religioso para fundamentar seus argumentos no direito internacional:

A idéia da paz vinculada ao direito será marcante em todo o movimento pacifista do século XIX; a obra de referência dessa idéia será a Paz Perpétua, que será considerada o marco da nova era do pacifismo, o ponto de partida de todos os esforços pacifistas dos séculos XIX e XX, e seu autor, o "fundador da filosofia da paz" (NOUR, 2004, p. 111, grifo do autor).

Para a teoria liberal da escolha racional os Estados são racionais e, portanto, escolhem cooperar, pois pensam em ganhos absolutos e não em ganhos relativos. Robert Axelrod em seu livro The evolution of cooperation (1984) utiliza a teoria dos jogos e o dilema do prisioneiro para explicar a cooperação. De acordo com este autor é preciso de confiança para haver cooperação, ela ocorre quando as interações entre os atores são repetidas várias vezes. A memória destas interações permite que os atores possam prever as ações dos outros e, portanto, se sentem mais seguros para cooperar. Daí a importância da repetição no processo de cooperação ao diminuir a insegurança dos atores em relação aos outros. Outro fator essencial para a cooperação é a comunicação entre os atores. Quando os atores se comunicam eles têm a possibilidade de redefinir seus interesses e estratégias, podendo chegar a acordos mutuamente benéficos:

the ability to communicate and cooperate can provide opportunities for the redefinition of interests and for the pursuit of strategies that would not be feasible if the only information available to states were about other state's preferences and available power resources. Just as allowing players in Prisoner's Dilemma to communicate with one another alters the nature of the game, so also institutions that increase the capability of states to communicate and to reach mutually beneficial agreements can add to the common grammar of statecraft and thus alter the results (KEOHANE e NYE, 2001, p. 282).

Nos anos setenta, a teoria da interdependência examina além da cooperação, o fenômeno do transnacionalismo, isto é, o surgimento de novos atores não estatais atuando para além das fronteiras estatais. Para NYE e KEOHANE (1977, 2001), a interdependência entre os atores no sistema internacional aumentaria a cooperação. Todavia, esta interdependência não é simétrica, pelo contrário, as diferenças de poder dos atores estão presentes nos acordos de cooperação.

Estes autores buscaram unir conceitos das teorias realista e liberal para criar um tipo-ideal, a interdependência complexa. A interdependência complexa não serve para explicar todos os eventos das relações internacionais, mas se aproximam muito de alguns casos de interdependência econômica e ecológica. Os autores definem interdependência como uma situação em que os efeitos são recíprocos para todos os atores envolvidos, ou seja, uma relação de mútua dependência. Estes efeitos resultam dos custos associados às transações internacionais. Em uma relação interdependente sempre haverá efeitos dispendiosos, do contrário, será uma 
relação de simples interligação ("interconnectedness"). Nas relações interdependentes, não é possível saber se os custos vão ou não exceder os benefícios mútuos decorridos das transações, isto vai depender do tipo de relação que existe entre os atores:

interdependent relationships will always involve costs, since interdependence restrict autonomy; but it is impossible to specify a priori whether the benefits of a relationship will exceed the costs. This will depend on the values of the actors as well as on the nature of the relationship (NYE e KEOHANE, 2001, p. 8).

NYE e KEOHANE (2001) apresentam como características fundamentais da interdependência complexa: a existência de múltiplos canais conectando as sociedades e a ausência de hierarquia entre os múltiplos temas da agenda internacional. Os múltiplos canais que têm conectado as sociedades podem ser formais ou informais e entre Estados, agências governamentais e atores transnacionais. $\mathrm{Na}$ ausência de hierarquia entre os temas da agenda internacional as metas dos Estados variam de acordo com a área temática, com a distribuição de poder em cada área temática e com os processos políticos utilizados em cada área.

$\mathrm{Na}$ situação de interdependência os temas da agenda internacional se tornam mais iguais em importância, o que têm levado os Estados e outros atores a competir para colocar os assuntos que consideram importantes para seus interesses na agenda internacional: "at the international level, we expect states and actors to shop among forums and struggle to get issues raised in international organizations that will maximize their advantage by broadening or narrowing the agenda" (KEOHANE e NYE, 2001, p. 29).

As organizações internacionais têm um papel maior nas situações de interdependência. Elas ajudam a estabelecer os temas da agenda internacional e agem como catalisadoras na formação de coalizões. E também são importantes arenas para iniciativas políticas de Estados menos poderosos.
A emergência de novos atores nãoestatais, como as organizações nãogovernamentais (ONGs), empresas transnacionais e movimentos sociais, colocam novas questões para a cooperação internacional. A cooperação entre atores não-estatais em diferentes países aponta para um outro tipo de cooperação, a transnacional, e sua relação com os Estados e sua soberania. NYE e KEOHANE (1977) caracterizam como uma relação transnacional aquela que atravessa a fronteira dos Estados e envolve atores ou organizações não governamentais, ainda que possa também envolver governos. Estas relações também podem conter assimetrias. Numa situação de interdependência as relações transnacionais podem afetar os resultados dos processos de barganha política (KEOHANE e NYE, 2001).

A interdependência também é um conceito trabalhado por outros autores como SOARES (2003), que define a interdependência como uma situação em que:

as unidades políticas se encontram de tal maneira implicadas umas nas outras, numa situação de um relacionamento de extrema relevância recíproca para todos os componentes do conjunto (SOARES, 2003, p. 600).

Para este autor, com o surgimento dos Estados e do sistema internacional, a interdependência passou a ser, e continua sendo a condição deste próprio sistema, em outras palavras, os Estados não conseguem fugir das relações com outros Estados. No entanto, a plena consciência desta condição de interdependência nem sempre existiu, sendo mais evidente a partir da segunda metade do século $X X$ com a intensificação das relações e dos fluxos (de mercadorias, capitais, pessoas, ideias) entre os Estados. Deste modo, a interdependência foi sempre um fenômeno presente nas relações internacionais e um postulado do Direito Internacional (SOARES, 2003).

No âmbito da proteção internacional do meio ambiente, a interdependência está presente, pois existe uma unicidade dos fenômenos físicos existentes no mundo que não pode ser quebrada 
por fronteiras políticas. Portanto, as tentativas visando regulamentar as ações sobre o meio ambiente precisam levar em consideração a interdependência entre os Estados e entre os fenômenos físicos do planeta, e que "a única maneira de se adotar um sistema normativo eficaz é por meio de normas instituidoras de direitos comuns e de deveres diferenciados, em função do desenvolvimento econômico dos Estados" (SOARES, 2003, p. 623). Soares ainda aponta que:

[...] a interdependência é um fenômeno indissociável da cooperação, na medida em que os Estados, ao pretenderem regular o meio ambiente que, na sua natureza físico-biológica é uma unicidade, a qual se encontra acima de qualquer divisão entre as soberanias dos Estados, exige o reconhecimento de que, para ser eficaz, qualquer regulamentação, inclusive em nível interno, necessita basear-se numa reunião e conjugação de esforços com vistas a uma finalidade comum (SOARES, 2003, p. 625).

Nos últimos anos do século $X X, 0$ neoinstitucionalismo liberal, principalmente com a teoria dos regimes, passa a ser a teoria mais utilizada pelos pesquisadores para explicar a cooperação internacional em questões ambientais e a criação de instituições internacionais ambientais (YOUNG, 1994; VOGLER, 1996). O neoinstitucionalismo tem sua origem na teoria das organizações. De acordo com esta teoria, as organizações reduzem os custos das trocas ligadas às imperfeições do mercado. As instituições sociais facilitariam a cooperação diminuindo os custos necessários para a obtenção de objetivos comuns.

Os estudos neoinstitucionalistas se concentraram em buscar os critérios para a existência de um regime, a sua efetividade, a sua robustez e a sua implementação. Um regime internacional é definido por Stephen Krasner como "um conjunto de princípios, normas, regras e de procedimentos de decisão, implícitos ou explícitos, em torno dos quais as expectativas dos atores convergem em um domínio específico" (apud SMOUTS, 2004, p. 139). Para ROMAN (1998), a análise dos regimes se concentra nos aspectos institucionais dos regimes. Este autor define os regimes internacionais como instituições sociais.

ROMAN (1998), em sua análise da implementação do Tratado de Cooperação Amazônica, caracteriza este como um regime internacional. Para este autor um regime internacional deve ser entendido como um processo gradual que ocasionalmente progride, devido ao que ele chama de momentos formativos ("formative moments"). Estes momentos corresponderiam às condições necessárias para que uma mudança no regime ocorra. Este autor concluiu que os regimes podem passar por momentos de inatividade até que as condições necessárias para sua evolução surjam, e que a implementação dos regimes leva muito tempo para se concretizar devido à interferência de diversos fatores domésticos e externos.

Nos últimos anos, a ideia de governança vem ganhando proeminência dentro da teoria neoinstitucionalista (SMOUTS, 2004). As análises sobre a governança tratam da cooperação internacional, mas não apenas entre Estados, e sim envolvendo outros atores que também atuam nas relações internacionais. Na obra organizada por James Rosenau e Ernest-Otto Czempiel, Governança sem governo (2000), os autores procuraram analisar conceitos como ordem, governança, instituições e poliarquia no novo contexto internacional:

compartilhamos um único ponto de vista a respeito dos temas fundamentais confrontados pelos analistas que buscam compreender as estruturas emergentes da política mundial. Notadamente, concordamos em que num mundo onde a autoridade sofre deslocamento contínuo, tanto exteriormente, no sentido das entidades supranacionais, como internamente, no sentido dos grupos subnacionais, é cada vez mais necessário verificar como pode existir governança na ausência de um governo (ROSENAU, 2000, p. 13).

O problema fundamental desta teoria é como coordenar a interdependência em um sistema de Estados soberanos na ausência de uma autoridade central supranacional, que 
poderia promover a ordem e a regulação das ações dos Estados e de outros atores internacionais, como supostamente ocorre no interior dos Estados (VOGLER, 1996). Governança se distingue de governo, embora os dois se refiram a sistemas de ordenação. O governo "sugere atividades sustentadas por uma autoridade formal, pelo poder de polícia que garante a implementação das políticas devidamente instituídas" (ROSENAU, 2000, p. 15). A governança se refere "a atividades apoiadas em objetivos comuns, que podem ou não derivar de responsabilidades legais e formalmente prescritas e não dependem, necessariamente, do poder de polícia para que sejam aceitas e vençam resistências" (ROSENAU, 2000 , p. 15). A governança é, portanto, mais ampla que governo, já que abrange além das instituições governamentais, normas, regras e condutas fora do âmbito governamental (ROSENAU, 2000). Para YOUNG (1994) um sistema de governança efetivo é aquele que provoca mudanças de comportamento que acabam por eliminar o problema que levou à sua criação.

Pode-se definir governança como um sistema de gestão que envolve diversos atores sociais estatais, da sociedade civil e empresários. Para RIBEIRO (2009) o objetivo deste sistema seria evitar conflitos a partir do ajustamento de interesses permitido pela reunião dos principais interlocutores em torno de um tema (ou problema) específico. A governança, portanto, facilita a formação de alianças e a cooperação. Mas ela também evidencia os conflitos frutos das assimetrias sociais e as diversas formas de resistência, organização e participação dos atores sociais.

RIBEIRO (2009) afirma que se pode analisar o tema da governança em diversas escalas, como a internacional, a nacional, a regional e a local. Para o autor, estas escalas se articulam e se complementam, porém não há hierarquia entre elas. A governança na escala internacional deve estar articulada às outras esferas, especialmente em um tema que é abordado em um tratado multilateral. No entanto, a governança nas diferentes escalas revela, muitas vezes, interesses e visões divergentes, e a escala internacional pode estar alheia aos contextos e problemas locais ou nacionais. A escala internacional da governança implica a análise das relações internacionais e do funcionamento do sistema internacional.

Para VOGLER (1996) as questões ambientais internacionais vêm sendo conduzidas dentro do clássico problema das relações internacionais de como ter certa ordem ou governança em um sistema anárquico de Estados soberanos, mas interdependentes. Os estudos sobre a cooperação em questões ambientais têm se concentrado principalmente no direito internacional e na organização, dentro da análise dos regimes. Atualmente, os pesquisadores estão se voltando para o papel das instituições, "this new approach assumes institutions to be critical to the setting of agendas, to the coordination of policy at the international level and most significantly to the environmentally related behaviour of governments and other actors" (VOGLER, 1996, p. 8). De acordo com esta abordagem, no contexto atual do sistema internacional existe a necessidade de instituições internacionais para que regulem os comportamentos responsáveis pela degradação ambiental.

Contrários a esta visão são os neorrealistas que, não estando convencidos da eficácia das instituições, continuam dando ênfase na estrutura de poder, chamando a atenção para a necessidade de um líder hegemônico nos regimes internacionais (VOGLER, 1996). Os neorrealistas afirmam que o exercício do poder hegemônico por um Estado, ou grupo de Estados, é o que permite a cooperação ou o regime internacional, em um mundo anárquico. Para KEOHANE (1984) a liderança hegemônica pode ajudar a criar um padrão de ordem, "hegemony depends on a certain kind of asymmetrical cooperation, which successful hegemons support and maintain" (KEOHANE, 1984, p. 49). Eduardo Viola, ao analisar o regime internacional de mudanças climáticas, acrescenta que "todo processo de construção de um regime internacional exige sempre a presença de pelo 
menos um ator que impulsione o processo e que seja capaz de liderar e sustentar o regime" (2003, p. 6).

A outra tradição das teorias das relações internacionais é a radical, devido à influência marxista. A partir dos anos oitenta começa a ocorrer um aprofundamento da relação entre o materialismo histórico e as relações internacionais, trazendo para o debate autores marxistas como Gramsci (GILL, 1993).

Dentre as teorias marxistas das relações internacionais a teoria da dependência é uma das poucas teorias de relações internacionais surgidas nos países latino-americanos e outros países periféricos. Entre os autores que contribuíram para esta teoria destaca-se: Raúl Prebish, Juan Noyola, Celso Furtado, Fernando Henrique Cardoso, Enzo Faletto, Theotonio dos Santos, Oswaldo Sunkel e André Gunder Frank. Trata-se de uma teoria com várias correntes que surgiu na década de 1960 para explicar o subdesenvolvimento da América Latina.

A teoria da dependência engloba vários autores que compartilham a ideia de que a dependência é uma condição histórica em que certa estrutura da economia mundial favorece alguns países em detrimento de outros. De acordo com Santos:

devemos caracterizar a dependência como uma situação condicionante. Um certo grupo de países tem a própria economia condicionada pelo desenvolvimento e expansão de outra economia. A relação de independência entre duas ou mais economias e entre estas e o comércio mundial, toma a forma de dependência quando alguns países (os dominantes) podem expandir-se e autoimpulsionar-se, enquanto outros (os dependentes) só podem fazê-lo como reflexo daquela expansão, que atua positiva ou negativamente sobre o próprio desenvolvimento imediato. De qualquer forma a situação básica de dependência conduz os países dependentes à condição de atrasados e explorados em relação aos dominantes. Estes dispõem do domínio tecnológico, comercial, financeiro e sócio-político - segundo os momentos históricos - que lhes permite impor condições de exploração e extração de excedentes produzidos internamente (SANTOS, 1976, p. 125).

Para os teóricos da dependência, o sistema internacional é constituído por dois conjuntos de Estados, os do centro (ou dominantes) e os da periferia (ou dependentes). As relações entre esses dois grupos de Estados são dinâmicas e reforçam os padrões de desigualdade internacionais. Os Estados periféricos sofrem grande influência de forças externas que acabam afetando sua condição socioeconômica. Esta situação é consequência da internacionalização do capital e sua consequente divisão internacional do trabalho.

Os países periféricos ao tentar seguir o modelo de desenvolvimento econômico dos países centrais não conseguiram reproduzi-lo. Os teóricos da dependência demonstraram que esse modelo dos países centrais é fruto de um processo histórico específico que inclui a exploração de colônias e países periféricos, e que não pode ser repetido (SANTOS, 2000).

O fenômeno da dependência não é apenas externo, pois ela também está presente na estrutura interna dos países periféricos sob diversas formas (social, ideológica e política) (SANTOS, 2000).

$\mathrm{Na}$ década de setenta teve início um debate mais amplo sobre as ideias da teoria da dependência em outras partes do mundo. $\mathrm{Na}$ África vários trabalhos estavam em curso sobre a questão do desenvolvimento, como os de Samir Amin. Outros autores como André Gunder Frank buscaram expandir a teoria da dependência para compreender a formação e evolução do capitalismo como uma economia mundial, por isso a estreita relação entre a teoria da dependência e a teoria do sistema-mundo, que acaba se desenvolvendo com Wallerstein (SANTOS, 2000).

A teoria da dependência gerou importantes trabalhos no campo das relações internacionais e da cooperação internacional ao apontar a existência de uma hierarquia de poder nas relações internacionais. Para os teóricos da 
dependência, o que caracteriza as relações internacionais entre os países do Norte e do Sul é a dominação e a exploração. A análise desta hierarquia de poder evidencia a cooperação assimétrica e a dependência dos países periféricos em relação aos países centrais. Duas formas de cooperação devem ser diferenciadas: a cooperação horizontal, também chamada de cooperação sul-sul, entre países da periferia do sistema, e a cooperação vertical, ou cooperação norte-sul, entre países centrais e países periféricos. A cooperação horizontal pode ser uma forma dos países periféricos se inserirem de forma diferenciada nas relações internacionais, estabelecendo novas regras. Os estudos sobre a dependência serviram de base para propostas de uma nova ordem internacional e para a formulação de estratégias de desenvolvimento:

la teoría de la dependencia constituye un paso más allá en la teoría del imperialismo en la medida en que enfatizan en el análisis de las formas, medios e instituciones de dominación internacional en su interacción con las dinámicas internas de los países del Norte y del Sur. Sus estudios incluyen el papel de las clases y sujetos sociales en las relaciones internacionales y la cooperación entre las clases explotadas en los países centrales y en los países dependientes (ESPINOZA, 2003, p. 7).

Ao analisar a cooperação assimétrica entre o Brasil e os países europeus e norteamericanos, a geógrafa Bertha BECKER (2006) argumenta que a cooperação internacional pode ser uma forma de coerção velada das potências mundiais, como meio para que estas possam intervir em certos países. No entanto, ela pode se tornar positiva se os países que a recebem souberem utilizá-la conforme seus interesses: "o diálogo e a diplomacia e, em particular, o fortalecimento dos vasos comunicantes entre Estado e sociedade civil, podem transformar essa coerção em instrumento de mudança positiva" (BECKER, 2006, p. 19).

A cooperação internacional assimétrica é evidente no caso da ajuda financeira internacional para o desenvolvimento. Como afirmam TOKATLIAN e CARVAJAL (1994) ao analisar a ajuda internacional para a América Latina, a cooperação para o desenvolvimento no pós-Guerra Fria visava "centralmente a confirmar y/o profundizar el modelo económico neoliberal que se generaliza en el subcontinente [...] demostrado cuando se observa la assistencia técnica y financeira de organismos como el Banco Mundial" (1994). Estes autores também apontam para a questão das condicionalidades nos acordos de cooperação. As cláusulas de condicionalidade nos acordos de cooperação são uma forma de prescrever certas políticas estatais, que devem ser cumpridas para que ocorra uma continuidade da ajuda internacional (CARVAJAL e TOKATLIAN, 1994).

Marc WILLIAMS (1998) faz uma comparação entre a ajuda financeira internacional para o desenvolvimento e a nova ajuda focada no desenvolvimento sustentável. Para este autor a inclusão da estratégia do desenvolvimento sustentável por parte de agências financiadoras, como o Banco Mundial, não mudou o caráter e as formas de dominação da ajuda financeira internacional:

sustainable development strategies adopted by international donors extend and reproduce forms of dominance. Sustainable development strategies do not depart radically from conventional aid policies. Situating sustainable development within the discourse on development reveals a continuity in the construction and maintenance of knowledge about the developing world. The focus on the poor and their relationship to the environment is informed by a commitment to growth. Sustainable development reproduces certain key themes of conventional developmentalism, e.g. population, and excludes from view critical issues such as militarization (WILLIAMS, 1998).

A ajuda internacional para o desenvolvimento (também chamada de assistência internacional ou cooperação técnica internacional) é um tipo de cooperação internacional que surgiu no pós-descolonização, 
e que já sofreu diversas críticas, entre elas dos próprios países que já foram colônias, para o estabelecimento de relações mais justas (SOARES, 2003, p. 608). Essas críticas também foram dirigidas ao próprio conceito de subdesenvolvimento e, por isso, os termos ajuda e assistência foram sendo substituídos por cooperação internacional e transferência de tecnologia.

A transferência de tecnologia entre países, tanto em sua forma bilateral quanto multilateral, também tem sido denominada de cooperação técnica internacional, embora ainda se encontre as expressões "auxílio", "ajuda" ou "assistência técnica". Trata-se de uma modalidade cujo objetivo é a facilitação e aceleração na formação de técnicos e de quadros administrativos, ou a transferência de uma tecnologia industrial, em países com menor grau de desenvolvimento tecnológico (SOARES, 2003).

O princípio do Direito Internacional mais revolucionário, em relação aos séculos anteriores, foi o reconhecimento de desigualdades existentes entre os Estados e a aplicação diferenciada das normas internacionais em relação aos Estados menos desenvolvidos (SOARES, 2003). A oposição entre países periféricos e países centrais já estava presente na primeira reunião da ONU sobre questões ambientais realizada em Estocolmo em julho de 1972. A segunda conferência, realizada no Rio de Janeiro em 1992, apresenta também esta situação. No Princípio 7 da Declaração do Rio sobre o Meio Ambiente e Desenvolvimento são definidas as responsabilidades comuns, porém diferenciadas dos Estados da atualidade (SOARES, 2003).

Se a cooperação internacional é usada por um Estado mais forte, impor suas preferências aos demais acaba interferindo na soberania destes. Por outro lado, muitas vezes os Estados alegam que a cooperação pode interferir em sua soberania quando não estão interessados em assumir maiores compromissos internacionais. $O$ papel da soberania na cooperação internacional varia quanto ao tipo de cooperação, se é vertical ou horizontal, isto é, se existe assimetria de poder entre os Estados envolvidos.

\section{Soberania estatal}

No Direito Internacional a soberania pode ser definida como "um poder supremo e independente em relação ao poder dos outros Estados" (SILVA, 2002, p. 165). E pode ser expressa de três formas: soberania interna (manutenção da ordem interna em um determinado território), soberania externa (não há subordinação a nenhuma autoridade internacional) e soberania nacional (direito do povo de eleger seus governantes).

O termo soberania surgiu juntamente com - Estado moderno em meados do século XVI (MATTEUCCI, 1986). A soberania estatal moderna foi consagrada formalmente pela Paz de Westfália, em 1648, que pôs fim à Guerra dos Trinta Anos. Estes acordos marcaram o fim da noção de um mundo cristão e o início de uma nova ordem internacional em que todos os Estados são soberanos em seus territórios, e que não existe nenhuma autoridade acima dos Estados no sistema internacional. A soberania surge juntamente com o Estado moderno. Neste sentido, a soberania é considerada "a culminação de um processo de expropriação das funções propriamente políticas, internas e externas, por parte do Estado Moderno" (TILIO, 2003, p. 18). Esta noção de soberania estatal está completamente vinculada à noção de território: "o território, tal como se forja, é claramente uma construção política, cuja primeira função é servir de suporte à soberania de um Estado que se cria" (BADIE, 1997. p. 45).

A soberania pode ser vista como um conceito político jurídico, pois concentra formas de força e de direito. Esta dualidade em relação à política e ao direito pode ser expressa pelas duas concepções clássicas de Jean Bodin e de Thomas Hobbes. Na concepção clássica de Jean BODIN (1992), a soberania é "o poder absoluto e perpétuo de uma República" (BODIN, 1992, p. 47), o soberano é visto como a fonte de toda a lei, tendo apenas algumas limitações como as leis naturais, os contratos firmados e as leis constitutivas da república. Para Bodin "a soberania reside no poder de fazer e de anular leis", tratase, portanto, de uma concepção jurídica, 
enquanto que para HOBBES (1979) a soberania é "o poder coativo de se fazer obedecer" (TILIO, 2003, p. 20).

Para RIBEIRO (2004b) a soberania surgiu de autores clássicos como Bodin, Maquiavel, Hobbes, Locke e Rousseau, e é aplicada nas relações entre países e em foros multilaterais. Com emergência de novos atores e temas na agenda internacional "é preciso rever a definição de soberania, sem precisar abandoná-la como defendem neoliberais" (RIBEIRO, 2004b, p. 27).

SOARES (2003) aponta que o Direito Internacional surgiu como uma afirmação da soberania absoluta. Pois, somente os Estados com um poder absoluto poderiam se autoimpor deveres em compromissos firmados com outros Estados soberanos, isto é, poderiam criar direitos e deveres para eles próprios.

Para MORGENTHAU (2000), a soberania é a autoridade suprema para aprovar e fazer cumprir leis em um determinado território, o que pressupõe "a independência em relação à autoridade de qualquer outra nação e a igualdade em relação às mesmas nos termos do direito internacional" (2000, p. 578). Para este autor as obrigações legais as quais um Estado aceita se submeter não limitam a sua soberania, pois não é a quantidade de acordos internacionais o que limita a soberania de um Estado, e sim a qualidade dos acordos, isto é, se eles afetam a sua autoridade suprema de legislador e aplicador da lei em um determinado território (2000).

De acordo com Morgenthau a hierarquia existente nas relações internacionais, a dependência de um Estado em relação a outro, não afeta a condição legal da soberania. E para o autor, a soberania é indivisível, pois se ela quer dizer autoridade suprema, não poderia haver mais de uma autoridade.

No entanto, outros autores contestam estas afirmações, pois, como afirma Lima:

[...] o próprio princípio da 'soberania absoluta' é, antes, uma construção doutrinária do que uma realidade prática. Simultaneamente à sua inauguração, os Estados foram levados a criar outras instituições que, de fato, negavam aquele princípio, como é o caso da imunidade diplomática, estabelecendo um espaço fictício, extraterritorial, no interior dos espaços nacionais (LIMA, 1996 p. 3).

Para Bachelet, a assinatura de acordos internacionais é uma característica da soberania, já que os Estados o fazem por livre vontade, sem influências externas, além do que, é o princípio de igualdade jurídica que levou os Estados a se comprometerem uns com os outros e estabelecerem obrigações recíprocas:

portanto, é preciso um livre consentimento para criar compromissos mútuos entre os Estados sempre livres de os romper ou de modificar o seu conteúdo, em função de sua soberania. A sua faculdade de manobrar no âmbito desta troca de vontades apenas conhece os limites que eles reconhecem a si próprios enquanto Estados plenamente soberanos. Em conseqüência, nada se opõe a que eles renunciem reciprocamente, num determinado domínio, a exercer a sua soberania. Podemos mesmo dizer que essa renúncia seria a mais perfeita expressão de sua soberania (BACHELET, 1995, p. 241).

Outras análises revelam que a soberania não é um atributo intrínseco do Estado, e sim uma instituição criada a partir da interação mútua entre eles, como tem sido afirmado por teóricos construtivistas (LAKE, 2003). A concepção realista de soberania, como a de Morgenthau, tem sido criticada por outros teóricos (BARKIN e CRONIN, 1994; RUGGIE, 1993; LAKE, 2003) por não levar em consideração aspectos considerados por eles como relevantes. Os autores construtivistas consideram esta concepção como fixa e ahistórica:

constructivists have emphasized that sovereignty, in both its internal and external faces, is a socially constructed trait. Although sovereignty and specially anarchy were once taken as enduring givens of international relations, they are now more usefull understood as what John Searle (1995) calls 'social facts' and what Alexander Wendt (1999), following 
Roy Bhaskar (1979), calls 'social kinds' (that is, social constructions that are produced and reproduced through the pratices of states). Thus, sovereignty is not exogenous to the system but produced through practice (LAKE, 2003, p. 308).

O neorrealista Stephen KRASNER (1999) faz uma análise da soberania na qual aponta desvios no que ele chamou de soberania Westphaliana. Sua intenção era mostrar como a soberania varia substancialmente entre as unidades do moderno sistema internacional. Krasner aponta que os problemas contemporâneos transfronteiriços e globais levam a uma soberania interdependente, em que os Estados precisam cooperar para tentar solucioná-los.

Para LAKE (2003) as análises de Krasner são incompletas, pois apesar de enfatizar os desvios da soberania, não os agrega em padrões, e também não identifica se esta questão dos desvios é importante para as relações internacionais. Partindo destes questionamentos, LAKE (2003) apresenta uma análise que incorpora a questão da hierarquia nas relações internacionais e sua influência para a soberania dos Estados.

Quando se trata de questões ambientais como a gestão dos recursos hídricos transfronteiriços, alguns autores (BECKER, 2006; MIYAMOTO, 1992) argumentam que, em alguns casos, o discurso ambientalista serve como argumento para a ingerência, ferindo assim o princípio da soberania. O que se alega para a ingerência, especialmente no caso da Amazônia, é que a destruição das florestas tropicais pode ter consequências globais e "partindo deste princípio a soberania deve, pois, ser colocada de lado, já que se trata de resolução de problemas comuns a todos os países, e não referidas especificamente a este ou aquele outro" (MIYAMOTO, 1992, P. 18). Isto ocorreu, por exemplo, quando o ex-presidente da França, François Mitterand, falou durante a Conferência do Meio Ambiente, em Haya, em 1989, "sobre a criação de uma Alta Autoridade Mundial para Assuntos Ambientais com capacidade de ingerência, o que significaria limitar as soberanias nacionais sobre os bens considerados de interesse para a humanidade, como a Amazônia" (AMAYO, 2007, p. 15).

Esta situação levou a uma separação clara entre as posições dos países do Norte e dos países do Sul, que tentam defender sua autonomia e o direito soberano de explorar os seus recursos naturais. MIYAMOTO (1992) afirma que os países em desenvolvimento nunca foram plenamente soberanos em suas decisões no plano internacional. Para este autor, apenas as grandes potência têm autonomia para decidir sobre questões internacionais, enquanto que aos outros países resta apenas o poder de barganha:

a impossibilidade de influenciar decisões mundiais tem levado, portanto, à polarização de comportamentos, de um lado os países desenvolvidos que ditam normas que regem o comportamento do sistema internacional, e de outro, os que apresentando limitada capacidade de barganha, mantêm-se ignorados mesmo nas decisões que os afetam diretamente, inserindo-se em um quadro préestabelecido francamente desfavorável, restando-Ihes pequenas margens de manobra, mas que são insuficientes para alterar os rumos do vento a seu favor (MIYAMOTO, 1992, p. 16).

A abordagem construtivista entende a soberania como dinâmica e socialmente construída, embora ela ocorra em todo o sistema (LAKE, 2003). Para o construtivismo as concepções de Estado e soberania não são pré-concebidas ou "a-históricas", como nas teorias neorrealistas e neoliberais, mas entendidas em sua historicidade. A grande contribuição da teoria construtivista é sua abordagem histórica e sociológica da soberania. Biersteker e Weber (1996) ao invés de partir da suposição de que todo Estado é soberano, estão interessados nos diversos modos que os Estados estão constantemente negociando a sua soberania externa. Os Estados são definidos a partir de suas reivindicações de soberania, e a soberania é definida a partir das interações e práticas dos Estados, portanto não é imutável. Trata-se de uma relação constitutiva entre Estado e soberania, em que os Estados estão 
sempre negociando o significado da soberania através de suas próprias práticas.

David STRANG (1996) faz uma análise da construção da soberania a partir das mudanças do significado desta no período do colonialismo e do imperialismo. No período imperialista, os países europeus construíram um discurso para deslegitimar a soberania dos países sob o poder imperial. O reconhecimento da independência e, portanto, da soberania das ex-colônias latinoamericanas também foi demorado e, mesmo quando a soberania foi reconhecida estes países continuaram dependendo fortemente dos países europeus, em especial, do Reino Unido. Esta análise apoiada na história permite entender porque os países sul-americanos estão sempre buscando o reconhecimento externo de sua soberania.

Strang argumenta que quando os europeus chegaram às terras da África e da Ásia, eles perceberam que os povos locais estavam organizados politicamente, e não poderiam ser ignorados, entretanto, não reconhecem certos direitos a eles, entre eles a sua soberania. Estes povos não eram "civilizados", não compartilhavam a mesma cultura, ideologia e instituições sociais dos europeus. Este discurso de não civilizados foi criado para que a opinião pública pudesse entender e apoiar a política imperialista, que passou a ser vista como uma missão civilizatória.

As ex-colônias americanas, apesar da demora, foram reconhecidas como Estados soberanos pelos países europeus, pois as elites destes países eram descendentes de europeus e, acima de tudo, compartilhavam o mesmo universo cultural e político. No entanto, no caso da América Latina, a dependência em relação à Europa continuou, além disso, o Reino Unido ainda usou a força armada para interferir na região ao menos quatro vezes de 1820 a 1914 (STRANG, 1996). Os países da América Latina buscaram o reconhecimento externo de sua soberania tentando se adequar aos padrões europeus, ao modelo europeu de Estado.

A relação entre soberania e cooperação envolve diversos aspectos. A cooperação pode ser vista como interferindo na soberania dos Estados, podendo ser usada como argumento para a ingerência ou, como no caso de uma gestão compartilhada de rios internacionais, como limitando a soberania dos Estados sobre os recursos em seu território. Pode também ser vista como um mecanismo de fortalecimento da própria soberania no sistema internacional, incentivando relações pacíficas e enfocando interesses comuns. A cooperação internacional para a gestão dos recursos hídricos tem como objetivo buscar soluções compartilhadas para problemas comuns e propõe a gestão compartilhada das bacias internacionais. Esta cooperação, na maioria das vezes, se dá na forma de instituições internacionais.

\section{Instituições e a gestão dos recursos hídricos transfronteiriços}

Para facilitar a cooperação os países criam instituições internacionais, com o intuito de guiar o comportamento dos atores em direção a objetivos comuns acordados por meio da cooperação. As instituições sociais são as regras do jogo que servem para definir práticas sociais, papéis e, teriam a função de guiar as interações entre os atores, resolver conflitos, facilitar a cooperação e aliviar os problemas de ação coletiva em um mundo de atores interdependentes (NORTH, 1996; MARCH, 1989; ROMAN, 1998). As instituições contribuem para a comunicação entre os atores, o que aumenta a confiança entre eles.

Oran YOUNG (1994) diferencia instituições de organizações, pois para ele as organizações são entidades materiais que possuem escritórios, equipamentos, equipe, orçamento, e personalidade jurídica. As organizações são instituições sociais, mas nem todas as instituições são organizações.

As instituições podem ser classificadas, para KRASNER (1999, p. 56), de acordo com sua institucionalização (definida como quando o comportamento é guiado por estruturas institucionais como princípios, normas e regras formais ou informais), ou de acordo com sua persistência ou durabilidade (entendida como um 
conjunto de princípios, normas e regras que persiste ao longo do tempo e da mudança dos contextos em que foram criadas).

Quanto mais os comportamentos dos atores se alinharem com as estruturas institucionais, maior é o grau de institucionalização. Os padrões de comportamento mais institucionalizados são aqueles que são tidos como normais ("naturais"), porque os atores não conseguem pensar em alternativas ou porque mesmo se conseguem pensar em alternativas, os constrangimentos são tão absolutos e fixos que não se consegue mudar o comportamento. Os padrões menos institucionalizados são aqueles em que as estruturas institucionais apesar de existirem não têm impacto sobre o padrão de comportamento. Para KRASNER (1999) um ambiente desprovido de estruturas institucionais seria semelhante a um estado de natureza em que o comportamento é guiado por interesses e ações calculadas a curto prazo e constrangidos apenas pelo poder dos outros atores. A eficácia do argumento dos neoinstitucionalistas estaria em demonstrar a institucionalização ou a durabilidade de uma instituição internacional (KRASNER, 1999).

As instituições ambientais são as normas que regulam os comportamentos dos Estados para que não causem danos ao meio ambiente, podendo ser governamentais ou nãogovernamentais. As instituições ambientais internacionais podem ser tanto acordos e convenções assinadas entre os Estados, regras informais e condutas, como também organizações internacionais. As instituições voltadas para a gestão compartilhada dos recursos hídricos transfronteiriços visam evitar possíveis conflitos entre os Estados devido ao caráter transnacional dos efeitos de sua degradação.

A gestão compartilhada dos recursos naturais é uma forma de lidar com os problemas comuns envolvendo os recursos hídricos transfronteiriços. Essa gestão envolve diversos atores, entre eles, diferentes instituições que, em alguns casos, são criadas para realizar a gestão específica de uma bacia internacional. Desde a segunda metade do século vinte foram criadas diversas instituições internacionais com o objetivo de conter o acirramento de tensões internacionais e desenvolver programas de gestão para bacias internacionais.

O debate sobre a questão da gestão compartilhada dos recursos hídricos transfronteiriços começou na década de 1960 na Europa. Anteriormente, e ao longo da história da humanidade, os povos compartilharam recursos hídricos, porém, o compartilhamento da gestão dos recursos hídricos (com o seu significado atual) teve início apenas nos anos sessenta:

Os países europeus foram os que mais avançaram nas novas formas de gestão das águas, em função de problemas de poluição interna e de que a maioria de suas bacias hidrográficas são compartilhadas entre mais de um Estado. Devido a características geográficas das bacias hidrográficas daquele continente, coube ao Conselho da Europa assumir a coordenação dos debates sobre esta questão, de modo a diminuir as tensões existentes entre aquelas nações. Para isso, foram negociados acordos e estabelecidas diretrizes de ação a serem seguidas pelos países da comunidade (ASSUNÇÃOO, 2002, p. 55).

A gestão dos recursos hídricos é realizada, em geral, através de um programa de gestão integrada de uma bacia hidrográfica. Deste modo, a bacia hidrográfica é a unidade de planejamento da gestão. O manejo ambiental da bacia corresponde a uma parte da gestão integrada e consiste na preservação, ou conservação das fontes de captação de água na bacia visando um melhor aproveitamento e controle da água (BRESSAN, 1996). Na década de 1990, foram sendo elaborados os princípios da gestão integrada dos recursos hídricos a partir da necessidade de lidar com múltiplas variáveis e desafios que envolvem as bacias hidrográficas.

De acordo com Lorenz et al. (apud FERRO, 2007) a gestão integrada de uma bacia hidrográfica é um tipo de gestão, visando o longo prazo, que abarca cada aspecto físico-biológico e cada interesse social de forma conjunta. Ainda segundo estes autores, para que ocorra a gestão integrada de uma bacia transfronteiriça devem 
ser atendidas algumas condições: uma boa atmosfera política entre os Estados que a compartilham; uma organização institucional de acordos e planos internacionais efetiva e modelos institucionais para executá-los; suporte operacional e cooperação técnica na coleta de informações e troca de conhecimentos, tais como de monitoração, pesquisa conjunta e planos. As bases da gestão integrada de uma bacia transfronteiriça são, portanto, as políticas, a cooperação e as instituições. Estes autores apontam que as ferramentas e instrumentos usados na gestão devem ser adaptados aos interesses econômicos, sociais e ambientais em jogo (LORENZ et al., apud FERRO, 2007). O sucesso da gestão de uma bacia vai depender também do grau de envolvimento (participação) dos atores sociais afetados, pois são estes que dependem dos recursos hídricos da bacia e que realizam as ações que impactam os mesmos.

A problemática dos recursos hídricos foi tratada pela Organização das Nações Unidas (ONU) na década de setenta na Conferência das Nações Unidas sobre Água realizada em Mar del Plata, em 1977. A partir de então esta discussão ganhou mais espaço e várias outras reuniões internacionais foram realizadas sobre o tema nas décadas seguintes. Em 1992 ocorre a Conferência das Nações Unidas para o Meio Ambiente e Desenvolvimento (CNUMAD), que tem como um de seus documentos finais a Agenda 21. Este documento trata da questão dos recursos hídricos em seu capítulo dezoito sobre a Proteção da Qualidade e do Abastecimento dos Recursos Hídricos: Aplicação de Critérios Integrados no Desenvolvimento, Manejo e Uso dos Recursos Hídricos. No entanto, foi em 1997 que a ONU realizou uma reunião para tratar especificamente sobre a gestão e o uso dos recursos hídricos transfronteiriços, a Convenção Internacional sobre a Utilização de Rios Internacionais para Fins Diferentes da Navegação ${ }^{2}$, realizada em Nova York. Esta convenção ainda necessita da adesão de mais países para entrar em vigor.

A necessidade de cooperação para solucionar os problemas dos recursos hídricos é expressa nesta última convenção em seu artigo sexto, que diz: "Watercourse States shall cooperate on the basis of sovereign equality, territorial integrity, mutual benefit and good faith in order to attain optimal utilization and adequate protection of an international watercourse". Esta convenção apresenta como princípios gerais: a utilização racional e equitativa dos recursos hídricos; a participação da sociedade nas decisões sobre a utilização destes; que a utilização racional e equitativa deve levar em conta fatores relevantes; a obrigação de não causar dano significativo a outro país; a obrigação de cooperar; a troca regular de dados e informações sobre o curso d'água ou bacia transnacional; a relação entre os diferentes tipos de uso da água. No entanto, não está explicito no texto da convenção o que seria "danos significativos", e como mensurá-los.

Ribeiro adverte que estas conferências sobre a água foram pouco efetivas, o que revela "a ausência de uma regulação internacional para o acesso à água" (2008, p. 19). Esta inexistência de regulação internacional favorece os interesses econômicos, permitindo sua comercialização em âmbito global, e os interesses estratégicomilitares de alguns países que podem por meio do uso da força ter acesso à água fora de seu território (RIBEIRO, 2008).

Para Ribeiro, estas conferências propõem o compartilhamento da soberania dos países que possuem bacias internacionais:

O aparato institucional em formação para a regulamentação do uso dos recursos hídricos em escala internacional propõe o compartilhamento destes, chocando-se com a soberania dos países e a prevalência de legislação nacional na exploração da água. Esses princípios constam da Declaração de Estocolmo, resultante da Conferência sobre Ambiente Humano, realizada em Estocolmo em 1972, e foram reafirmados na Declaração do Rio, ratificada em 1992, na CNUMAD (RIBEIRO, 2008, p. 76).

No caso da Convenção de 1997, a questão da soberania é central já que se trata de rios que correm em mais de um território. No entanto, "a obrigatoriedade da boa convivência e da soberania 
compartilhada levam ao esvaziamento do documento" (RIBEIRO, 2008, p. 98).

Reconhecem-se no direito internacional dois tipos de soberania envolvendo a questão de bacias internacionais: a soberania territorial absoluta e a integridade territorial absoluta (RIBEIRO, 2008). Na soberania territorial absoluta o Estado usufrui dos recursos hídricos de um curso de água transfronteiriço, independentemente das consequências que isso possa ter para os demais países e não precisa informá-los sobre suas atitudes. Já no modelo da integridade territorial absoluta, é considerado propriedade comum das partes o curso de água transfronteiriço. Todas as atividades que os países pretendam realizar no curso de água teriam que ser informadas, e só seriam permitidas aquelas que não colocassem em risco seu aproveitamento pelos outros países ribeirinhos.

Na Convenção de 1997 é utilizada outra teoria, a da "soberania territorial limitada", em que cada Estado tem sua autonomia reconhecida para utilizar a água desde que não cause danos para os países vizinhos. Para Ribeiro, "esse modelo é o que melhor se aplica à gestão compartilhada de uma bacia hidrográfica e seus cursos de água" (2008, p. 95).

Os poucos Estados que assinaram a Convenção de 1997 ( 16 assinantes e 15 ratificações em 2007) nada podem fazer sem a participação dos seus vizinhos com os quais compartilham cursos de água. Esta convenção está, portanto, longe de conseguir solucionar os problemas em torno dos recursos hídricos transfronteiriços:

a proposição, elaboração, discussão e definição de uma Convenção a partir da Assembléia Geral resultou em um corpo normativo extremamente idealista. [...] Uma convenção idealista que encontre dificuldades em ser ratificada mantém o problema sem solução. Enquanto isso perdurar, as práticas políticas e ambientais de países que compartilham recursos hídricos serão baseadas na sua capacidade de intervenção militar, impondo o realismo político clássico e, o que é pior, o uso desigual dos recursos hídricos na escala mundial (RIBEIRO, 2008, p. 99).

Em um estudo sobre os recursos hídricos internacionais chamado "Basin at Risk Project", do departamento de Geociências da Universidade de Oregon (Estados Unidos), os autores (WOLF, 2003; GIORDANO, 2003) analisaram as mais de 200 bacias internacionais e procuraram identificar indicadores históricos de conflito ou cooperação em torno destas bacias. Eles criaram uma escala de intensidade que vai do conflito à cooperação com 15 pontos, e analisaram as teorias e os indicadores mais citados sobre os conflitos envolvendo bacias internacionais. Seus resultados revelaram que a cooperação é mais frequente do que os conflitos em torno das bacias internacionais. Outra conclusão relevante do estudo é a de que a possibilidade de conflito aumenta em uma bacia onde ocorreu uma mudança do sistema físico ou institucional que exceda a capacidade da bacia e suas instituições de absorver esta mudança. Como mudança física, analisou a construção de barragens e como mudança institucional, a internacionalização de uma bacia.

Os autores sugerem que os estudos posteriores sobre bacias internacionais devem desenvolver os seguintes tópicos: a existência, força e estrutura dos tratados sobre águas internacionais e outros mecanismos institucionais relevantes; o nível de desenvolvimento das instituições encarregadas de gerenciar a água em cada Estado ribeirinho; a qualidade da governança na bacia e as condições, tais como densidade populacional, PIB per capita, que pode afetar a capacidade do governo de lidar com mudanças; e as incertezas ligadas as regime hídrico da bacia.

Em outro trabalho, Giordano e Wolf analisam os tratados sobre bacias internacionais e apontam que falta robustez na maioria deles:

water allocations, for example, the most conflictive issue area between co-riparian states, are seldom clearly delineated in water accords. [...] Enforcement mechanisms are also absent in a large percentage of the treaties. Finally, international basins with agreements remain in 
the minority. Formal management institutions have been established in only 117 of the 263 international basins and even within these, few include all nations riparian to the affected basins, which precludes the integrated basin management advocated by the international community (GIORDANO, 2003, p. 168).

Existem três escalas principais em que atuam as instituições internacionais para a gestão dos recursos hídricos. A escala internacional onde atuam organizações internacionais tais como as Nações Unidas através de convenções assinadas em seu âmbito, e também através da atuação de organismos como o Programa das Nações Unidas para o Meio Ambiente (PNUMA) e o Fundo Mundial para o Meio Ambiente (sigla em inglês GEF Global Environment Facility). Outra escala é a regional, como a assinatura de acordos entre os países de uma região do mundo, como por exemplo, no âmbito da União Europeia. A terceira é a escala de uma bacia hidrográfica como é o caso do acordo entre Índia e Paquistão em torno da bacia do rio Indo, o "Indus Waters Treaty" (BRADNOCK, 2003; ALAM, 2002).

$\mathrm{Na}$ escala das bacias hidrográficas Giordano e Wolf em vários trabalhos (2003, 2007, 2008) fazem uma revisão dos acordos sobre bacias internacionais no último século e apontam que a escala das bacias hidrográficas é a mais apropriada para a gestão dos recursos hídricos pois, geralmente, existem interesses comuns entre os Estados ribeirinhos relativos ao aproveitamento da bacia, além do que buscam um acordo que reflita as necessidades e condições específicas da bacia (GIORDANO, 2008).

CONCA (2006) lança a indagação sobre a emergência de um regime global de rios internacionais baseado no conjunto de princípios existentes nos acordos internacionais sobre bacias internacionais. Este autor acredita que não se pode falar em regime, primeiro, ele aponta que nem todas as bacias internacionais possuem um acordo, e as que possuem os acordos variam em extensão, profundidade e escopo. No entanto, afirma que "at least some of these accords can be said to meet the definition of an international regime as rules of the game that delimit the range of legitimate or admissible behavior in a specific context of activity'" (CONCA, 2006, p. 103).

Isto leva a uma complexa questão quanto à relação entre um processo global de construção de normas e princípios para bacias internacionais e o crescente conjunto de acordos na escala das bacias. No âmbito global existe a Convenção das Nações Unidas de 1997 sobre a utilização dos rios transfronteiriços que busca criar um conjunto de princípios e normas internacionais, e na escala das bacias muitos destes princípios são encontrados nos acordos:

although the Watercourses Convention was not approved until 1997, its central principles became apparent much earlier, during the ILC deliberations; many of these principles trace their origins to developments in the 1960s. Convergence on these norms across individual basin-specific treaties, which involve highly heterogeneous political, economic, and ecological situations, could be read as significant evidence of a global normative pull. On the other hand, the causal relationship could be the opposite, in the sense that the global framework simply reflects accumulated practice in the basin-specific treaties" (CONCA, 2006, p. 103).

Neste aspecto, os analistas têm apresentado diferentes abordagens sobre a relação entre as diferentes escalas. MACCAFFREY and SINJELA (apud CONCA, 2006) afirmam que importantes princípios da Convenção (de 1997) estão presentes em alguns acordos recentes na escala das bacias, assim como, a Convenção reflete os princípios acumulados no desenvolvimento sobre o direito das águas. Já WOLF e HARMNER (apud CONCA, 2006) acreditam que são poucos os acordos de bacias internacionais que contém os princípios da Convenção que resultaram de mais de trinta anos de negociações. Estes autores apresentam evidências de que existe uma grande distância entre o conteúdo dos acordos de bacias e o conteúdo da Convenção.

it appears that a few incorporate all riparian states within the basin to which they apply. Few make even rudimentary links to others 
issues, much less the comprehensive linkages required for enforcement mechanisms, or even the "back-door" binding power that many regime theorists posit through processes of monitoring, information exchange, and actively shared governance. It is also noteworthy that the pace of codification of basin-specific treaties has slowed in recent decades (CONCA, 2006, p. 105).

Os acordos sobre bacias internacionais e a Convenção representam para Conca (2006) um padrão esporádico, fragmentado e ás vezes ambíguo de cooperação em torno dos rios transfronteiriços, que coloca em dúvida a questão da emergência de uma regime global seja via a estrutura global da Convenção, seja através dos acordos de bacias. Entretanto, aponta que a escala das bacias internacionais talvez seja a que contém os maiores avanços, "even if most of the world's shared basins remain uncovered by international accords, those for which accords are in place could be converging on a set of norms for shared governance" (CONCA, 2006, p. 106).

Embora seja possível destacar vários avanços nos acordos sobre bacias internacionais, vulnerabilidades institucionais ainda podem ser identificadas. Das 263 bacias internacionais, 158 não possuem nenhum tipo de estrutura de cooperação entre os Estados ribeirinhos. Das 105 bacias que apresentam alguma instituição, cerca de $20 \%$ delas possuem acordos multilaterais, a maioria são acordos bilaterais, apesar de dois terços das bacias com instituições serem compartilhadas por três ou mais Estados. Além disso, os acordos que levam em conta a gestão, monitoramento e avaliação da qualidade da água, resolução de conflitos e participação pública ainda são minoria. Desta forma, a grande maioria dos acordos continua sem os instrumentos e ferramentas necessários para uma gestão eficiente a longo prazo (GIORDANO, 2008).

GIORDANO e WOLF (2008) apontam que, como resultado das experiências deste último século, as estruturas para a gestão compartilhada dos recursos hídricos devem contar com: estruturas adaptáveis de gestão permitindo que as contribuições do público, as novas informações e tecnologias possam ser incorporadas; critérios flexíveis e claros de distribuição e qualidade da água; distribuição equitativa dos benefícios; e mecanismos de resolução de conflitos bem detalhados.

Conca, ao analisar os acordos ao nível de bacias, retoma alguns aspectos de Giordano e Wolf, que também aponta para a questão da distribuição dos acordos no tempo e no espaço, revelando que os acordos existentes não abarcam nem a metade das bacias internacionais e têm diminuído o ritmo de acordos assinados nas últimas décadas. Este autor também chama a atenção para o número de participantes nos acordos revelando que a maioria deles são bilaterais enquanto que a maioria das bacias internacionais estão localizadas nos territórios de três Estados ou mais. Outro fator relevante apontado por CONCA (2006) são os princípios contidos nos acordos, o padrão temporal destes princípios e a correlação entre eles. Enquanto alguns princípios estão presentes em grande parte dos acordos (como o princípio da consulta, troca de informações, e resolução pacífica de disputas), outros não (como o princípio do uso eqüitativo e o principio de não causar dano significativo). A proteção ambiental é um princípio que têm recebido grande ênfase a partir de 1992, devido ao aumento da preocupação em relação às questões ambientais a partir da conferência das Nações Unidas realizada nesta data. CONCA (2006) também afirma haver um modesto crescimento do princípio de não causar dano significativo e da criação de comissões permanentes de bacias.

Tanto CONCA (2006) quanto WOLF (2003) apontam para a baixa institucionalização da questão dos recursos hídricos no âmbito internacional. Para RIBEIRO (2008), esta baixa institucionalização é reflexo dos interesses econômicos e políticos de atores poderosos como as corporações multinacionais, organizações internacionais como o Banco Mundial e potências mundiais:

a edificação de ordem ambiental da água ainda é frágil. Ela carece de um aparato institucional [...]. A presença marcante, no caso da água, 
de grandes empresas transnacionais destituiu o caráter público das discussões, resultando em programas de privatização desenvolvidos mundo afora (p. 153).

\section{Considerações finais}

Os atores principais da cooperação internacional são os Estados e as instituições internacionais. Os Estados exercem a soberania sobre seu território e sobre os recursos hídricos presentes neste território. Estes Estados estão separados uns dos outros pelas fronteiras políticas que delimitam os seus territórios. No entanto, alguns recursos naturais são transfronteiriços, isto é, atravessam as fronteiras entre os Estados e, portanto, estão presentes em mais de um território. Os recursos hídricos quando são transfronteiriços geram uma situação de interdependência entre os Estados que os compartilham, pois a poluição e a degradação ambiental gerada à montante pode impactar o Estado à jusante.

Esta situação de interdependência leva os Estados a cooperarem uns com os outros para evitar conflitos em torno dos recursos compartilhados. Em alguns casos, para facilitar a cooperação, os Estados criam instituições internacionais com o objetivo de regular as ações destes em relação aos recursos hídricos compartilhados. No caso dos recursos hídricos transfronteiriços existe uma convenção, a Convenção Internacional sobre a Utilização de Rios Internacionais para Fins Diferentes da Navegação (de 1997), mas que ainda não está em vigor porque poucos países a assinaram e ratificaram. Também existem acordos e organizações internacionais no âmbito das bacias internacionais, nos quais os maiores avanços em termos de institucionalização vêm ocorrendo.

\section{Notas}

${ }^{1}$ Cooperação não é o mesmo que integração. $\mathrm{Na}$ cooperação as soberanias são preservadas e o objetivo central é a coordenação de políticas para atingir objetivos comuns. Já a integração envolve um certo grau de supranacionalidade, de independência da organização em relação aos Estados.

${ }^{2}$ No decorrer deste trabalho esta convenção será referida como Convenção de 1997.

\section{Referências Bibliográficas}

ANTIQUERA, Daniel C. A Amazônia e a política externa brasileira: análise do Tratado de Cooperação Amazônica (TCA) e sua transformação em organização internacional (1978-2002). Dissertação (Mestrado em Relações Internacionais). Programa San Tiago Dantas, Convênio PUC-SP/UNESP/UNICAMP. Campinas, 2006.

ALAM, U. Questioning the water wars rationale: a case study of the Indus Waters Treaty. The Geographical Journal. V. 168, n. 4, dec 2002, p. 341-353.
ALLISON, G. T. Essence of decision: explaining the Cuban Missile Crisis. Boston: Little Brown, 1971.

ALLISON, G. T. e HALPERIN, M. H. "Bureaucratic politics: a paradigm and some implications". World Politic. John Hopkins University Press. n. 24, 1972.

ALLISON, G. T. e ZELIKOW, P. Essence of decision: explaining the Cuban missile crisis. Longman, 1999.

ARON, R. Paz e guerra entre as nações. Brasília: IPRI/FUNAG, 2002. 
ARON, R. Estudos Políticos. Brasília: Ed. UNB, 1985.

ASSUNÇÃO, F. N.; BURSZTYN, M. A. Conflitos pelo uso dos recursos naturais. In: THEODORO, S. H. Conflitos e uso sustentável dos recursos naturais. Rio de Janeiro: Garamond, 2002, p. 53-69.

AXEROLD, R. The evolution of cooperation. New York: Basic Books, 1984.

BACHELET, Michel, s.d. Ingerência Ecológica Direito Ambiental em questão. Lisboa: Insituto Piaget, 1995.

BALSIGER, J.; NEIL, K.; VANDEVEER, S. Actors, norms, and impact: recent international cooperation theory and the influence of the agentstructure debate. Annual Review of Political Science. 2004, p. 149-175.

BARKIN, J. S.; CRONIN, B. The state and the nation: changing norms and rules of sovereignty in international relations. International Organization. MIT Press, v. 48, n. 1, winter 1994, p. 107-130.

BERNAL-MEZA, R. Síntese da evolução do pensamento latino-americano em relações internacionais. In: PROCÓPIO, A. (org.). Relações Internacionais: os excluídos da arca de Noé. São Paulo: Hucitec, 2005, p. 209-259.

BIERSTEKER, T. J. e WEBER, C. The social construction of state sovereignty. In: BIERSTEKER, T. J. e WEBER, C. (ed.). State sovereignty as social construct. New York/ Cambridge: Cambridge University Press, 1996.

BODIN, J. Los seis libros de la republica. Colección Clásicos del Pensamiento. Madrid: Tecnos, 1992.

BRADNOCK, R. W.; BRICHIERI-COLOMBI, S. Geopolitics, water and development in South Asia: cooperative development in the GangesBrahmaputra delta. The Geographical Journal. V. 169 , n. 1, mar 2003, p. 43-64.

BRESSAN, D. Natureza e gestão racional: uma leitura para o terceiro mundo. In: BRESSAN, $D$. Gestão racional da natureza. São Paulo: Hucitec, 1996, p.75-100.
BURCHILL, S. Liberalism. In: BURCHILL, S, LINKLATER, A. et al. Theories of International Relations. New York: Palgrave Macmillan, 2005, p. 55-83.

CARR, E. H. Vinte anos de crise 1919-1939. Brasília: EdUNB, 2001.

CARVAJAL, H., L. e TOKATLIAN, J. G. Tendencias de la cooperación internacional en la posguerra fría. Colombia Internacional. Bogotá: Universidad de los Andes, n. 25, enero-marzo 1994.

CAUBET, Christian. G. A água doce nas relações internacionais. Barueri: Manole, 2006.

COELHO, Pedro M. P. Fronteiras na Amazônia: um espaço integrado. Brasília, DF: Fundação Alexandre de Gusmão, 1992.

CONCA, Ken. Governing water: contentious transnational politics and global institution building. Massachusetts: MIT Press, 2006.

COSTA, W. M. Geografia Política e Geopolítica: discursos sobre o território e o poder. São Paulo: Hucitec / EdUSP, 1992.

DONNELLY, J. Realism. In: BURCHILL, S, LINKLATER, A. et al. Theories of International Relations. New York: Palgrave Macmillan, 2005, p. 29-54.

DUDA, A. M.; UITTO, J. I. Management of transboundary water resources: lessons from international cooperation for conflict prevention. The Geographical Journal, v. 168, n. 4, dez, 2002, p. 365-378.

ESPINOSA, E. La cooperación internacional en las relaciones internacionales de Cuba. Disponível em: <http://www.redem.buap.mx/word/ 2005eugenio.doc>. Acessado em: ago 2008.

GILL, S. (ed.). Gramsci, historical materialism and international relations. New York/Cambridge: Cambridge University Press, 1993.

GIORDANO, Meredith A.; WOLF, Aaron. Sharing waters: Post-Rio internacional water management. Natural Resources Forum. Oxford, Malden: Blackwell Publihing, 2003, n. 27 , p. $163-171$. 
GIORDANO, Meredith A.; WOLF, Aaron.. International River Basin Management: Global Principles and Basin Practice. Dissertação de Ph.D em Geografia apresentada ao Departamento de Geociências da Universidade do Estado de Oregon (EUA). 2002. Disponível em: <http:// www.transboundarywaters.orst.edu/publications/ Giordano-Meredith-2002.pdf>. Acesso em: dez. 2007.

. The world's international freshwater agreements. Disponível em: <http:// www.transboundarywaters.orst.edu/publications/ a t I a s / a t I a s_ h t m I / fore word / internationalAgreements.html >. Acessado em: 10 fev 2008.

GODARG, O. A gestão integrada dos recursos naturais e do meio ambiente: conceitos, instituições e desafios de legitimação. In: VIEIRA, P. F.; WEBER, J. (org.). Gestão de recursos naturais renováveis e desenvolvimento: novos desafios para a pesquisa ambiental. São Paulo: Cortez, 2000, p. 201-266.

HAESBAERT, R. e GONÇALVES, C. W. P. A nova des-ordem mundial. São Paulo: Ed. UNESP, 2006.

HALLIDAY, F. Repensando as relações internacionais. Tradução de Cristina Soreanu Pecequilo. Porto Alegre: Ed. UFRGS, 2007.

HALPERIN, Morton H. Bureaucratic Politics and foreign policy. Washington: Brookings Institution, 1974.

HOBBES, T. Leviatã ou Matéria, forma e poder de um estado eclesiástico e civil. Coleção Os Pensadores. São Paulo: Abril, 1979.

HURRELL, A.; KINGSBURRY, B. The International Politics of the Environment. Oxford: Clarendon Press, 1992.

IMBER, M. F.; VOGLER, J. (ed.). The environment and International Relations. Nova York: Routledge, 1996.

KANT, I. A Paz Perpétua. Tradução de Marco A. Zingano. Porto Alegre: L\&PM, 1989.

KEOHANE, R. O.; NYE, J. Power and Interdependence: world politics in transition. Boston: Little Brown, 2001.
KEOHANE, R. O.; NYE, J. Transnational relations and world politics. Harvard University Press, 1977.

KEOHANE, R. O. After hegemony: cooperation and discord in the world political economy. Princeton: Princeton University Press, 1984.

KRASNER, S. Sovereignty: organized hypocrisy. Princeton: Princeton University, 1999.

International regimes. Ithaca: Cornell University Press, 1983.

LAFFERRIÈRE, E. e STOETT, P. J. International relations theory and ecological thought: towards a syntesis. New York: Routledge, 1999.

LAKE, D. New Sovereingty. International Studies Review. V.5, 2003, p. 303-323.

MACHADO, L. O. Sistemas, fronteiras e território. Rio de Janeiro: UFRJ, 2002.

Interações na fronteira Brasiléia - Cobija,

Brasil - Bolívia. Rio de Janeiro: UFRJ, 2001.

MACHADO, L. O. e STEIMAN, R. Limites e fronteiras internacionais: uma discussão históricogeográfica. Rio de Janeiro: UFRJ, 2002.

MARCH, J. G.; OLSEN, J. P. Rediscovering Institutions: the organizational basis of politics. New York: Free Press, 1989.

MATTEUCCI, N. Soberania. In: BOBBIO, N.; MATTEUCCI, N. e PASQUINO, G. Dicionário de Política. Brasília: Ed. UNB, 1986.

MILNER, Helen. International theories of cooperation among nations: strengths and weaknesses. World Politics. John Hopkins University Press, v. 144, n. 3, apr. 1992, p. 466496.

MORAES, A. C. R. Meio Ambiente e Ciências Humanas. São Paulo: Hucitec, 1994.

.Território, região e formação colonial: apontamentos em torno da geografia histórica da independência brasileira. Ciência e Ambiente. Santa María: Universidade Federal de Santa Maria, n०33, jul/dez 2006, p. 9-16.

. Território, poder e justiça: comentários

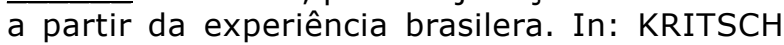


e RICUPERO (orgs). Força e Legitimidade: novas perspectivas. São Paulo: Humanitas, 2005, p.113-139.

MORAES, A. C. R. (org.). Ratzel. São Paulo: Ática, 1990.

MORGENTHAU, Hans. A política entre as nações. Coleção Clássicos IPRI. São Paulo: IMESP/UNB/ IPRI, 2004.

NORTH, Douglass C. Institutions, institutional change and economic performance. Cambridge: Cambridge University Press, 1996.

NOUR, S. À Paz Perpétua de Kant: filosofia do direito internacional e das relações internacionais. São Paulo: Martins Fontes, 2004.

OSIANDER, A. Sovereignty, International Relations and the Westphalia Myth. International Organization. V. 55, n. 2, Spring 2001, p. 251287.

PAUL, D. E. Sovereingty, survival and the Westphalian blind alley in International Relations. Review of International Studies. V. 25, 1999, p. 217-231.

PRECOTT, J. R. V. The geography of frontiers and boundaries. Londres: Hutchinson \& Co., 1965.

RAFFESTIN, C. Por uma geografia do poder. São Paulo: Ática, 1993.

RIBEIRO, Wagner C. A ordem ambiental internacional. São Paulo: Contexto, 2001.

. Geografia Política da Água. São Paulo: Annablume, 2008.

- Geografia Política e Recursos Naturais. Mercator. UFC, v. 3, n. 5, 2004a, p. 73-78.

- Impasses da governança da água no Brasil. In: RIBEIRO, W. C. (org.). Governança da água no Brasil: uma visão interdisciplinar. São Paulo: Annablume, 2009.

Aqüífero Guarani: gestão compartilhada e soberania. Estudos Avançados. São Paulo: IEAUSP, v. 22, n. 64, 2008, p. 227-238.

Geografia Política da Água. Tese de Livre Docência. São Paulo: Faculdade de Filosofia,
Letras e Ciências Humanas, Universidade de São Paulo, 2004b.

ROBBINS, P. Political ecology in political geography. Political Geography. V 22, 2003, p. 641-645.

ROMAN, Mikael. The implementation of international regimes: the case of the Amazon Cooperation Treaty. Uppsala: Uppsala University Press, 1998.

ROSENAU, J.; CZEMPIEL, E. Governança sem governo: ordem e transformação na política mundial. São Paulo: Imprensa Oficial, 2000.

Governança, ordem e transformação na política mundial. In: ROSENAU, J.; CZEMPIEL, E. Governança sem governo: ordem e transformação na política mundial. São Paulo: Imprensa Oficial, 2000.

SÁNCHEZ, Joan-Eugeni. Geografia Política. Madrid: Editorial Síntesis, 1992.

SANTOS, T. A teoria da dependência: balanços e perspectivas. Rio de Janeiro: Civilização Brasileira, 2000.

A crise da teoria do desenvolvimento e as relações de dependência na América Latina. In: JAGUARIBE, H.; FERRER, A.; SANTOS, T. e WIONCZEK, M. A dependência político-econômica da América Latina. São Paulo: Loyola, 1976.

SOARES, G. F. S. A interdependência dos Estados no campo da proteção internacional ao meio ambiente. In: OLIVEIRA, O e RI JÚNIOR, A. D. (org.). Relações Internacionais: interdependência e sociedade global. Ijuí: unijuí, 2003, p. 599-627.

SMOUTS, Marie-Claude. A cooperação internacional: da coexistência à governança mundial. In: SMOUTS, Marie-Claude (org.). As novas relações internacionais: práticas e teorias. Brasília: Ed. Universidade de Brasília, 2004, p. 129-153.

Tropical forests, international jungle: the underside of global ecopolitics. New York: Palgrave Macmillan, 2003.

STRANG. D. Contested sovereignty: the construction of colonial imperialism. In: 
BIERSTEKER, T. J. e WEBER, C. (ed.). State sovereignty as social construct. New York/ Cambridge: Cambridge University Press, 1996, p. 22-49.

VALLAUX, C. Suelo y el estado. Madrid: Daniel Jorro, 1914.

VIOLA, E. As complexas negociações internacionais para atenuar as mudanças climáticas. In: TRIgueiro, A. (org.). Meio Ambiente no século 21. Rio de Janeiro: Sexante, 2003, p. 183-198.

VOGLER, J. Introduction: the environment in International Relations: legacies and contentions. In: IMBER, M. F.; VOGLER, J. (ed.). The environment and International Relations. Nova York: Routledge, 1996.

WALT, S. International Relations: one world, many theories. Foreign Policy. N. 110, 1998, p. 29-46.

WALTZ, K. Theory of International Politics. New York: McGraw-Hill, 1979.

WEBER, Max. Economia e Sociedade: fundamentos da sociologia compreensiva. Brasília: Ed. UNB, 1999.
WEBER, S. Institutions and change. In: DOYLE, M. W.; IKENBERRY, G. J. New thinking in international relations theory. Boulder (EUA), Oxford: Westview Press, 1997, p. 229-265.

WILLIAMS, Marc. Aid, sustainable development and the environmental crisis. International Journal of Peace Studies. v.3, n. 2, 1998. Disponível em: <http://www.gmu.edu/academic/ijps/vol3_2/ Williams.htm>. Acessado em: out 2008.

WOLF, Aaron; STAHL, Kerstin.; MACOMBER, F. Macomber. Conflict and cooperation within international river basins: the importance of institutional capacity. Annual meeting of the International Studies Association. Portland, 2003. Disponível em: <http:// www.transboundarywaters.orst.edu/ publications/conflict_coop/ $>$. Acessado em: dez. 2007.

YOUNG, Oran. International Governance: protecting the environment in a stateless society. Ithaca: Cornell University Press, 1994.

International Regimes: toward a new theory of institutions. World Politics. John Hopkins University Press, v. 39, n. 1 , out. 1986, p. 104-122

Trabalho enviado em outubro de 2009 Trabalho aceito em dezembro de 2009 